INTERNATIONAL HIGHER EDUCATION, Number 72. Summer 2013

Pages 5-7

\title{
The False Halo of Internationalization
}

JENNY J. LEE

Jenny J. Lee is associate professor at the Center for the Study of Higher Education, University of Arizona, Tucson. E-mail: jennylee@email.arizona.edu.

Internationalization has come to the forefront as countries and their institutions strategize to participate in today's global society. Internationalization can be likened to an arms race of international students, scholars, programs, and linking an institution to individuals and activities outside its national borders. While massive efforts are now being made to internationalize, less attention is paid to determining the quality and educational return in investments once the activities are set up. This effect of internationalization too easily overlooks the human aspect of migration and exchange, which is well documented as being quite uneven globally. In short, a danger occurs in blindly promoting internationalization, without careful consideration of its intended purposes and unintended consequences.

Being cautious and paying attention to the qualitative experiences of international students and scholars can yield major insights leading to improved benefits and coordinating the intended diplomatic goals of internationalization. Two cases will be presented on the experiences of understudied international scholars and students, which offer implications on how internationalization should be critically assessed and practiced. 


\section{SCIENTIFic Postdoctoral LABor}

International postdocs are a fundamental but often overlooked population in understanding scientific-research production. In the United States and in the United Kingdom, postdocs are heavily concentrated in the science, technology, engineering, and mathematics fields. These contingent researchers serve the countries' scientific-knowledge creation, given current domestic-skill shortages. Meanwhile, providing postdocs from abroad is plentiful, as international scholars tend to seek out positions in the United States and western Europe at the most highly ranked global universities.

While all postdocs had at least some aspirations toward becoming faculty, international postdocs were far less inclined. This international population holds two tiers of academic labor-one theoretical (United States and Europeans) and the other technical (Asians), as determined by faculty supervisors' stereotypes. These views then translated to different levels of work responsibilities and, ultimately, career paths-lab supervisors on temporary contracts and tenuretrack science faculty. Based on this research, particular groups (i.e., Asians) are especially vulnerable as they tend to be assigned tasks that may not lead toward faculty positions. Faculty supervisors' decisions may be based on unchecked perceptions about cultures and countries of origin.

In today's global knowledge society, the principles of efficiency suggest that several part-time or short-term researchers are a better financial investment on scientific knowledge production, compared to a single, tenured full professor. Consequently, the term "postdocs for life" is becoming increasingly common, 
because opportunities for advancement and permanent job security are limited. Questions arise, however, when considering whether such activities constitute "internationalization." Based on a superficial observation, the hiring of international scholars appears certainly to qualify. When observed more critically, however, the potential exploitation of scholars from developing countries runs directly counter to the good-spirited message of internationalization.

\section{STUdent ATHLETES FROM ABROAD}

As a second example, international student athletes are heavily recruited in the United States as a way to bring athletic prestige to an institution. As in the case of international postdocs, international student athletes are sought later to promote an institution's reputation above and beyond their domestic supply. African athletes have been researched strongly represented in track and field. Instances of social isolation, verbal insults, and harassment were identified, in many ways similar to previous findings on other international student populations. Among the most pervasive misperceptions about African student athletes, in particular, are that these student athletes prioritize a future professional career in sports over academics. Consequently, many are funneled to majors that might be less academically demanding, to accommodate for their training and competitions, but left with degrees that have little relevance when they return home.

In the United States, a highly regarded athletic program can generate hundreds of millions of US dollars from corporate sponsorships, private donations, ticket sales, and more. In order to maintain or increase a team's 
competitiveness, recruiting student athletes from abroad is commonplace. As an added benefit, these international students can be showcased to demonstrate an institution's internationalization efforts. These students also gain from receiving scholarships and the opportunity to study at a university with more resources than what might be available at home. Such a win-win situation appears appealing to both parties but, when examined more carefully, concerns arise. The quality of these student athletes' experiences tend to be ignored, despite the considerable efforts that are made to recruit them. The career trajectories of these individuals are also left unexamined, especially considering that top-ranked athletes can pursue a professional athletic career, without a college education.

\section{A Social And Educational Responsibility}

In sum, it is naïve and irresponsible to perceive internationalization as being inherently good. Internationalization is not merely a set of observable activities but also involves social and education responsibility. As demonstrated in the previous examples, internationalization efforts do not automatically result in improved education opportunities and experiences, let alone greater diplomacy between participating countries.

Internationalization potentially reflects the dominant interests of the host recipients, than in the intended spirit of mutual collaboration and cultural exchange. In the higher education context, faculty and administrators must not limit planning to fiscal considerations, as is often the case. The burden of internationalization beyond the initial setup should be on the international hosts, not the invitees. When international scholars and students report unmet 
expectations, discrimination and unfair treatment, and harassment from the host community, the problem should be addressed by those who recruited them, not left to the sufferers.

The research has found that the source of discrimination is often our own domestic students and even faculty, who ironically are occurring in education sites-including classrooms. As such, the reported incidents in many ways reflect a failure of the education system to educate its own members on the value of internationalization and the educational benefits that international students and scholars need to offer.

Many domestic students cannot afford to study abroad but can have an international experience in their own institutions. Among international students' most cited disappointments is the lack of social relationships with domestic students. While university activities to facilitate social exchange are plentiful, these events tend to be poorly attended with limited interest from local students. Higher education institutions can internationalize by educating their own domestic students on the value of internationalization and acquiring basic global competencies, such as being able to effectively communicate with individuals in foreign accents, possess knowledge about diverse cultures outside its borders, and network with those from overseas, as vital to success in this globalizing society.

Receiving countries and institutions need to avoid exploiting international students or scholars in the interest of global prestige or economic revenue. While internationalization is part of today's academic landscape, how we practice it is yet to be determined. 